\title{
NAS TRILHAS DO -R RETROFLEXO
}

Silvia Figueiredo BRANDÃO

Universidade Federal do Rio de Janeiro

Resumo: Neste texto, focaliza-se o $-\mathrm{R}$ retroflexo no Português do Brasil, no intuito de fazer um levantamento de alguns registros de sua ocorrência em diferentes falares, sem discriminar suas manifestações como tepe ou como aproximante. Com base nos trabalhos comentados, indicam-se, num mapa, suas áreas de abrangência.

Palavras chave: Português do Brasil; Variação lingüística;-R retoflexo.

Abstract: In this paper, retroflex - $\mathrm{R}$ is observed in Brazilian Portuguese, in order to make a survey of some registers of its occurrence in different dialects (realizations as a tap or an approximant are not discriminated). On the basis of the reported studies, the areas where it appears are indicated in a map.

Key Words: Brazilian Portuguese; Linguistic variation; Retroflex -R.

Resumen: En este texto, se enfoca la -R retrofleja nel Portugués de Brasil, con el objetivo de hacer un inventario de algunos registros de su ocurrencia en diferentes dialectos (no se discriminan sus concretizationes como tap o como aproximante). Basado en los trabajos comentados, se indican, en un mapa, sus areas de abrangencia.

Palabras clave: Portugués de Brasil;Variación lingüística; R retrofleja.

\section{Introdução}

Dentre os tipos de pronúncia que diferenciam o Português do Brasil das demais variedades do Português, as mais significativas são, sem dúvida, as realizações retroflexas de $-R$. Mencionadas, desde inícios do século passado, nos primeiros estudos de natureza dialectológica, até hoje se procura determinar sua origem, tanto do ponto de vista fonológico, quanto do ponto de vista sócio-histórico. Neste artigo, busca-se (a) fazer um levantamento de alguns registros de sua ocorrência (sem discriminar suas manifestações como tepe ou como aproximante), bem como dos contextos em que incide e, (b) com base nesse levantamento, realizado em trabalhos de diferentes 
épocas e orientações metodológicas, indicar, num mapa, suas áreas de abrangência.

\section{Alguns dos primeiros registros sobre a concretização retroflexa de - R}

$\mathrm{O}-\mathrm{R}$ retroflexo foi, durante certo tempo, apenas mencionado como característica do chamado dialeto caipira, denominação com que Amadeu Amaral cunhou o falar "do território da antiga província de São Paulo" e que, até fins do século XIX, teria dominado "em absoluto a grande maioria da população", estendendo sua influência "à própria minoria culta".

Em 1920, ano de publicação de $O$ dialeto caipira, seu autor chamava a atenção para o fato de que transformações de natureza vária vinham gradativamente detendo "o processo dialetal ali em curso" e, conseqüentemente, marginalizando os"genuínos caipiras", já então "acantoados" em pequenas localidades, o que determinaria o desaparecimento daquele falar "em prazo mais ou menos breve". (AMARAL, 1976, p. 11-12)

No entanto, em trabalho publicado em 1974, Rodrigues demonstrou que, na região de Piracicaba, ainda se encontravam algumas das variantes descritas 54 anos antes por Amadeu Amaral, entre as quais as africadas $\left[\mathrm{t} \int \mathrm{d}_{3}\right]$ e o $-\mathrm{R}$ retroflexo. Da mesma forma, Head (1978, p. 34) - particularmente interessado no estudo desse segmento ${ }^{1}$, - citou várias monografias que indicavam a vitalidade desse fone em território paulista e em Minas Gerais, como se verá adiante.

A respeito do $-\mathrm{R}$ retroflexo manifestaram-se alguns filólogos, entre os quais Serafim da Silva Neto, Silveira Bueno e Gladstone Chaves de Melo. Silva Neto (1963) assim a ele se referiu:

Há que falar, agora, de uma área muito carregada de tipicismo: estendese por três Estados: sul de São Paulo, sul de Mato Grosso, e norte do Paraná, mas devemos reconhecer que está ainda longe de ter sido traçada com rigor. Em todo o caso, o ponto de irradiaçao parece ter sido São

\footnotetext{
${ }^{1}$ Em trabalho publicado em 1987 (cf. referências bibliográficas), Head apresenta sua hipótese sobre a origem do $-\mathrm{R}$ retroflexo.
} 
Paulo e o povoamento bandeirante. Essa é a região do País onde se acumulam os sons mais estranhos à língua comum. Trata-se: [...]

c) de um $\overline{\mathbf{r}}$ inter epós-vocálico, lingual e guturalizado, assim descrito por Amadeu Amaral:

Na sua prolação, em vez. de projetar a ponta contra a arcada dentária superior, movimento este que produz a modalidade portuguesa, a lingua leva os bordos laterais mais ou menos até os pequenos molares da arcada superior e vira a extre-midade para cima, sem tocá-la na abóbada palatal. Não há quase nenbuma vibraşão tremulante'

Trata-se, pois, de um r retroflexo. [...]

Em outro trabalho (1960, p. 74-75), em que trata, principalmente do $[\mathrm{t} f]$ e do $\left[\mathrm{d}_{3}\right]$ observa:

Há ainda um outro fato que nos parece digno de atenção. É a existência, nas mesmas áreas caipiras, de um fonema que ainda não apareceu no sistema consonântico português. Trata-se de um r inter e post-vocálico (arara, carta) de natureza linguo-palatal e guturalizado.

As pessoas que já o ouviram descrevem-lhe a pronúncia como realizada entre o $r$ e o l. Assim Alves de Camargo soa qualquer coisa como Arlves de Camarlgo. É curioso comparar isso com o que Ehrenreich (citado a outro propósito por Mattoso Camara no seu estudo Alguns radicais Jê, 1959, pág. 9) diz do $\mathbf{r}$ indigena: $r$ ist der in den meisten südamerikanischen Sprachen sich findende Mittellaut zwischen rund l.

Silveira Bueno (apud HEAD, 1978, p. 22-23) ${ }^{2}$ chama a atenção para a vitalidade do $r$ retroflexo ainda nessa época, embora, de novo, só acrescentasse notícia sobre sua ocorrência também em Goiás:

As características deste nosso falar continuam, portanto, ainda hoje, $e$ muito vivas e persistentes até entre as pessoas mais cultas, desmentindo a afirmaço de Amaden Amaral, (segundo a qual o dialeto caipira estava em vias de desaparecimento). Existem áreas onde tais características são

\footnotetext{
${ }^{2}$ Trata-se do artigo "O dialeto caipira”, publicado no Jornal de Filologia IV (3/ 4), São Paulo: 1-33.
} 
mais vivas que em outras e, de um modo geral, podemos afirmar que são aquelas cidades de fundação bandeirantes: Itu, Porto Feliz, Tietê, Atibaia, Bragança, Piracicaba, Tatuí, Limeira, Taubaté. Foram os bandeirantes paulistas que disseminaram por essas áreas a sua maneira de falar e as (sic) levaram aos Estados que surgiram de seus descobrimentos de minas especialmente Mato Grosso, Goiás, sul de Minas, norte do Paraná.

Melo (1975, p. 106), por sua vez, assim se manifestou:

Tal ré característico do Norte de São Paulo e Sul de Minas, e nele se transforma sistematicamente o -l final de sílaba. Quem já viajou por aquelas bandas sabe que, basta transpor-se a Mantiqueira, aparecem meninos vendendo "paster de carne", com o seu errezinho particular. Esta consonância aproxima-se bastante do r final de sílaba americano, que figura por exemplo em form, porém é mais intenso. Está para or inglês como o nosso rinicial está para o jespanhol ou ch alemão.

Várias hipóteses foram levantadas a propósito da existência dessa variante, preocupando-se, como se pôde verificar, os referidos filólogos em determinar-lhe o ponto de irradiação (São Paulo) e o meio de difusão (as entradas e bandeiras) por outras áreas do território brasileiro (Norte do Paraná, Sul de Minas, Goiás, Mato Grosso).

Hoje, parece importante retomar a questão de sua distribuição geográfica, pois, como testemunham os atlas lingüisticos regionais já publicados e diversos outros estudos, seu alcance espacial parece ser mais amplo do que se supunha. ${ }^{3}$

\section{0 que revelam os atlas lingüísticos}

No Atlas Prévio dos Falares Baianos (ROSSI et al., 1963), encontram-se 59 registros da retroflexa, em 19 pontos de inquérito,embora no centro-leste do Estado (Feira de Santana e Chapada Diamantina) se concentre o maior número de realizações. A

\footnotetext{
${ }^{3}$ Tal constatação já havia sido feita pela autora deste estudo em sua tese de Doutoramento (BRANDÃO, 1988) e mencionada também em Brandão, 1991.
} 
retroflexa ocorre sempre em posição pós-vocálica ( $\mathrm{V}$ - ou $\mathrm{CV}-$ ), antes das oclusivas $/ \mathrm{p} /, / \mathrm{t} /, / \mathrm{k} /, / \mathrm{d} /, / \mathrm{g} /$, das fricativas $/ \mathrm{v} / \mathrm{e} / \mathrm{s} / \mathrm{e}$ das nasais $/ \mathrm{m} / \mathrm{e} / \mathrm{n} /$.

No Esboço de um Atlas Lingüistico de Minas Gerais (RIBEIRO et al., 1977), há 63 ocorrências da retroflexa - no mesmo contexto (Ve CV-), diante de $/ \mathrm{k} /, / \mathrm{t} /, / \mathrm{d} /, / \mathrm{v} / \mathrm{e} / \mathrm{m} /$-, e, ainda, uma carta com a respectiva isófona, limitada ao sul de Minas, sobretudo na zona fronteiriça com o Estado de São Paulo e parte do Rio de Janeiro, e recobrindo, integralmente, as zonas do Triângulo e do Sul e determinadas áreas do Alto Parnaíba, Alto São Francisco, da Mata e Campos das Vertentes.

Nas cartas do Atlas Lingüistico da Paraíba (ARAGÃO; MENEZES, 1984), só ocorrem três casos de retroflexa, nas palavras argueiro, aguardente e espírito (com síncope do [i] postônico), respectivamente, nas localidades de Princesa Isabel (Microrregião de Serra do Teixeira), Esperança (Microrregião do Agreste da Borborema) e João Pessoa (Microrregião do Litoral Paraibano), portanto, no Sudoeste e no Leste do Estado, embora, no volume 2, ao fazer a análise fonético-fonológica do material coletado, as autoras afirmem que a retroflexa pode ocorrer em posição pós-vocálica, antes de /t/ e de /d/, exemplificando com os vocábulos morta, corta, sertão e cordão (p. 49). Como se comentará no item seguinte, a variante está presente na fala da capital (SKEETE, 1995).

O Atlas Lingüistico de Sergipe (FERREIRA et al., 1987) apresenta, em 14 cartas, 47 ocorrências de retroflexa, em situação pósvocálica, 41 delas na fala de Brejo Grande, Propriá e Curralinho, conforme se observa na tabela a seguir. Quatorze casos correspondem à permuta de $-\mathrm{L}$ por $-\mathrm{R}$ e 31 , à concretização de $/ \mathrm{R} /$. De acordo com a classificação apresentada, há 04 casos de vibrante retroflexa múltipla e os demais de vibrante retroflexa simples. 


\begin{tabular}{|l|c|c|c|}
\hline Ponto/Localidade & Homem & Mulher & Total \\
\hline 52- Tomar do Geru & 04 & -- & 04 \\
\hline 53- Estância & 01 & & 01 \\
\hline 57-Laranjeiras & 01 & & 01 \\
\hline 61-Brejo Grande & 09 & 02 & 11 \\
\hline 62- Propriá & 14 & 02 & 16 \\
\hline 65- Curralinho & 05 & 09 & 14 \\
\hline Totais & $\mathbf{3 4}$ & $\mathbf{1 3}$ & $\mathbf{4 7}$ \\
\hline
\end{tabular}

Tabela 1 - Ocorrências de -R retroflexo no ALS-I

No Atlas Lingüistico de Sergipe-II (CARDOSO, 2005) há apenas doze ocorrências de [c], pós-vocálico, também em Brejo Grande, Propriá e Curralinho e, ainda, em Gararu (ponto 64), nos vocábulos borbulha, cargueiro, escaldado, porta, quarto, salta-riacho, tuberculoso e volta.

No Esboço de um Atlas Lingüistico de Londrina (Aguilera, 1987), verifica-se ser a retroflexa uma variante significativa do falar daquele Município, uma vez que é detectado em todos os doze pontos de inquérito, sempre em situação implosiva, antes das oclusivas $/ \mathrm{p} /$, /b/, /t/, /k/, /g/ e das fricativas / s / e / z /. Como variante de -L pós-vocálico só aparece nas lexias calcanhar, alfaiate e sol.

No Atlas Lingüistico do Paraná (AGUILERA, 1994), a variante retroflexa ocorre fundamentalmente em coda silábica, difundindo-se pela maior parte do Estado, como atesta, não só a carta 187 que apresenta "as isófonas de -r-em travamento silábico, com base em parteira", mas também as de números 138 (sol), 140 (anzol), 141 (calcanhar), em que ocorre como variante de $-\mathrm{L}$ em coda. Em grupo consonantal, aparece, também com grande produtividade, na carta 154 (clara).

No Atlas Lingüistico Etnográfico da Região Sul do Brasil (KOCH et al., 2002), a carta sintética 48-53 define o "Limite meridional de /r/ retroflexo em (cla)R(a), (go)R(dura), (co)R(ta), (co)R(da), (fe)R(vendo) e (calo)R, vocábulos que são objeto de cartas específicas. 
Observa-se que a área correspondente à retroflexa concentrase no Paraná - onde apenas em seis das 100 localidades em que se realizaram inquéritos não se registrou a variante (Microrregiões de Campos de Guarapuava, Sudoeste Paranaense e Médio Iguaçu) -, e adentra por determinadas áreas de Santa Catarina, deixando de fora todas as comunidades do Rio Grande do Sul, embora lá se observem ocorrências esparsas em oito dos 95 pontos considerados (677, 679, 709, 754, 820, 834, 839 e 840).

Em Santa Catarina, num total de 80 localidades, trinta encontram-se na área de $-\mathrm{R}$ retroflexo, conforme se discrimina na tabela 2, em que se separam duas subáreas: a primeira, que se desenha, em direção ao sul, a partir da fronteira centro leste com o Paraná; a segunda, isolada, na área litorânea sudeste.

Fora da zona de abrangência da isófona, observa-se a variante ainda em Praia Grande, um dos três pontos da Microrregião Colonial do Sul Catarinense, em Sangue do Veado, um dos três pontos da Microrregião do Litoral Sul Catarinense e em Marechal Bormann, na Microrregião do Oeste Catarinense, que conta com 12 pontos de inquérito

\begin{tabular}{|c|c|c|}
\hline Microrregião & $\begin{array}{c}\mathbf{N}^{\mathbf{o}} \text { de pontos } \\
\text { de inquérito } \\
\text { considerados }\end{array}$ & $\begin{array}{c}\text { Pontos de inquérito } \\
\text { com ocorrência } \\
\text { de retroflexa }\end{array}$ \\
\hline $\begin{array}{c}\text { Colonial de } \\
\text { Joinville }\end{array}$ & 5 & $477,478,481$ \\
\hline $\begin{array}{c}\text { Colonial do } \\
\text { Alto Itajaí }\end{array}$ & 4 & 504,517 \\
\hline $\begin{array}{c}\text { Campos de } \\
\text { Curitibanos }\end{array}$ & 6 & $486,488,490,492$ \\
\hline $\begin{array}{c}\text { Colonial do } \\
\text { Rio do Peixe }\end{array}$ & 9 & $434,435,438,439$, \\
\hline $\begin{array}{c}\text { Planalto de } \\
\text { Canoinhas }\end{array}$ & 7 & $464,459,470,471$, \\
\hline \multicolumn{2}{|c|}{} & $472,473,475$ \\
\hline $\begin{array}{c}\text { Florianópolis } \\
\text { Litoral de } \\
\text { Laguna }\end{array}$ & 6 & 297 \\
\hline Carbonífera & 5 & 572,582 \\
\hline $\begin{array}{c}\text { Litoral Sul } \\
\text { Catarinense }\end{array}$ & 3 & 569,581, \\
\hline $\begin{array}{c}\text { Campos de } \\
\text { Lages }\end{array}$ & 5 & 584 \\
\hline
\end{tabular}

Tabela 2 - Áreas de ocorrência de -R retroflexo em Santa Catarina, segundo a carta 48-53 do ALERS 
Ainda no ALERS, na carta 27 (calção), vê-se a permuta de L pós-vocálico pela retroflexa em 27 comunidades do Paraná e três, de Santa Catarina.

Embora no Atlas Lingüistico Sonoro do Pará (RASKY, 2004) não se registre nenhum caso de retroflexa, Lima (2003), em estudo de natureza sociolingüística sobre $\mathrm{o}-\mathrm{R}$ pós-vocálico interno na fala urbana do Município de Cametá, numa amostra de 1.154 dados selecionada do Corpus do Projeto Atlas Geo-sociolingüístico do Pará, detectou $9 \%$ de casos de tepe retroflexo, num universo de 20 informantes estratificados por gênero, faixa etária (15-35 anos; mais de 45 anos), escolaridade (sem escolaridade; $2^{\circ} / 3^{\circ}$ graus) e renda (baixa; média/ alta). Segundo o autor, a variante está relacionada "aos indivíduos do sexo masculino, da segunda faixa etária [mais de 50 anos] e de renda baixa" (p. 63),.

No Atlas Lingüistico do Amazonas (CRUZ, 2004), no Atlas Geolingüístico do Litoral Potiguar (PEREIRA, 2007), no Atlas Fonético do entorno da Baía de Guanabara (LIMA, 2006), que abrange quatro municípios da Região Metropolitana do Rio de Janeiro, não se encontram registros de $-\mathrm{R}$ retroflexo.

\section{$3 \mathrm{O}$ que revelam outros estudos}

Entre os estudos relacionados por Head no artigo anteriormente mencionado (1978, p. 25), incluem-se o de sua própria autoria, que revela dados sobre Franca-SP, e, ainda, os de Maria Zilda Zapparoli, sobre Itu-SP (1970); de Iório Fernandes Rodrigues, sobre Piracicaba-SP (1974); de Gies Istre, sobre São Luís de Paraitinga-SP (1971); e de João Alves Pereira Penha, sobre São Domingos-MG (1972). ${ }^{4}$

\footnotetext{
${ }^{4}$ Os trabalhos mencionados por Head são aqui indicados da forma como foram citados em seu artigo: ISTRE, Gies. 1971. A phonological analysis of Brazilian Portuguese Dialect. Tese de doutoramento inédita. Louisiana State University and Agricultural and Mechanical College; PENHA, João Alves Pereira. 1972. Aspectos da linguagem de São Domingos: tentativa de descrição da linguagem rural brasileira.Franca: s. ed.; RODRIGUES, Fernando Iório. 1974. O linguajar matuto. Trabalho datilografado do Curso de Aperfeiçoamento em Letras, Universidade Federal de Alagoas, Maceió; ZAPPAROLI, Zilda Maria. 1970. Comportamento fonético-fonológico da região de Itu. Dissertação de Mestrado inédita, Universidade de São Paulo.
} 
Com base na síntese por ele apresentada, elaborou-se o quadro a seguir, que contém os contextos em que ocorre a realização retroflexa na fala das comunidades citadas. Como se verifica, é no contexto pós-vocálico que ela se mostra mais produtiva, embora, em Capivari, tenha ocorrido também em situação intervocálica e, em Piracicaba, em todos os contextos arrolados.

Quadro 1 - Contextos de ocorrência de -R retroflexo na fala de comunidades citadas por Head (1978)

\begin{tabular}{|c|c|}
\hline Contextos & Localidades \\
\hline & Franca-SP \\
$\begin{array}{c}\text { Pós-vocálico } \\
\text { interno e } \\
\text { externo }\end{array}$ & $\begin{array}{c}\text { São Domingos-MG } \\
\text { São Luís do Paraitinga-SP } \\
\text { Capivari-SP } \\
\text { Piracicaba-SP }\end{array}$ \\
\hline Intervocálico & Capivari-SP \\
& Piracicaba-SP \\
\hline $\begin{array}{c}\text { Em grupo } \\
\text { consonantal }\end{array}$ & Piracicaba-SP \\
\hline
\end{tabular}

Nesse mesmo estudo, Head (1978, p. 23), que também acreditava numa ampla distribuição da retroflexa pelos falares brasileiros, mencionando a tese de Istre, afirma que ele observa que "o r caipira alterna com ø em posição final de palavra, e cita vários autores no intuito de mostrar que esta variante ocorre numa região extensa, que, segundo ele, abrange os estados do Ceará, Rio Grande do Norte, Pernambuco, Amazonas, Goiás e Minas Gerais (235239)".Diz, ainda, em uma nota (p.30), que já tivera “ocasião de observar (porém sem poder analisar) seu uso por alguns falantes do interior de Alagoas". 5

$\mathrm{Na}$ tese de Furlan (1982, p. 92), indicam-se 31 realizações da retroflexa. Esse número, que parece pouco significativo diante das 113

\footnotetext{
${ }^{5}$ Como não se tem notícia de estudos sobre os falares do Rio Grande do Norte, Pernambuco, Amazonas e Alagoas que comprovem essa afirmativa, não se incluirão essas áreas no mapa ao final deste estudo.
} 
ocorrências de vibrante alveolar (num total de 166), torna-se expressivo, pelo fato de ter sido obtido numa região de Santa Catarina onde há forte influência do adstrato luso-açoriano. Vale transcrever suas observações (o autor divide o Falar Açoriano-Catarinense em três subfalares):

A realização retroflexa ocorreu apenas em cinco dos 20 informantes do FC [Falar Central] e em apenas sete casos, o que contrasta vivamente com o do FS [Falar Sulista], onde quatro dos cinco informantes o proferiram como retroflexo em 10 ocorrências, e com o FN [Falar Nortista], onde três dos cinco informantes o realizaram como tal, em 14 ocorrências. Os dados sugerem, pois, a conclusão de que a retroflexão acompanha melhor os que alveolarizam o $/ r \mid$ do que os que o velari zam, fator que parece estar ligado ao fator ponto el ou modo de articulação. Pelo que se verifica, é na região do litoral Norte do Estado (Barra Velha, Araguari, São Francisco do Sul) que se encontra a maior incidência desse fone, em posição final de sílaba, diante de consoante velar. (p. 94).

Brandão (1988), para a análise realizada em sua tese, de cunho dialectológico, sobre o falar de comunidades pesqueiras, de perfil rural, do Município de Campos (Mundéus, São Benedito, Furadinho, Ponta Grossa dos Fidalgos, e Farol de São Tomé), na Região Norte do estado do Rio de Janeiro, aplicou, a um informante ${ }^{6}$ em cada uma dessas comunidades, um Questionário Reduzido, de 145 perguntas, em que 71 delas correspondiam a $-\mathrm{R}$ em diferentes contextos.

Verificou-se que, em posição final externa, o rótico é apagado ou se concretiza como aspirada ( 2 casos) e, quando em início de vocábulo ou intervocálico correspondente $\mathrm{a}-\mathrm{R}$ forte, realiza-se categoricamente como fricativa velar.

Nessa amostra, o $-\mathrm{R}$ retroflexo ocorre em três contextos: intervocálico $\left(V_{-} V\right)$, em ataque complexo de sílaba $\left(C_{-} V(C)\right)$ e em final de sílaba interna $((\mathrm{C})(\mathrm{C}) \mathrm{V}-)$, como se expõe na tabela 3.

\footnotetext{
${ }^{6}$ Informantes do sexo masculino, entre 34 e 47 anos.
} 


\begin{tabular}{|c|c|c|c|c|c|c|}
\hline \multirow{3}{*}{ Localidades } & \multicolumn{6}{|c|}{ Contextos } \\
\hline & \multicolumn{2}{|c|}{$V-V$} & \multicolumn{2}{|c|}{$\begin{array}{c}(\mathrm{C})(\mathrm{C}) \mathrm{V}- \\
\text { (interno) }\end{array}$} & \multicolumn{2}{|c|}{$\mathrm{C}-\mathrm{V}$} \\
\hline & Oco & Perc. & Oco & Perc. & Oco & Perc. \\
\hline Mundéus & $25 / 25$ & $100 \%$ & $18 / 20$ & $90 \%$ & $15 / 23$ & $65 \%$ \\
\hline S. Benedito & $2 / 25$ & $8 \%$ & $2 / 18$ & $11 \%$ & $1 / 23$ & $4 \%$ \\
\hline Furadinho & $21 / 24$ & $88 \%$ & $18 / 20$ & $90 \%$ & $14 / 23$ & $61 \%$ \\
\hline $\begin{array}{c}\text { Ponta } \\
\text { Grossa dos } \\
\text { Fidalgos }\end{array}$ & $3 / 17$ & $18 \%$ & $2 / 19$ & $10 \%$ & $3 / 24$ & $13 \%$ \\
\hline $\begin{array}{l}\text { Farol de } \\
\text { São Tomé }\end{array}$ & $23 / 25$ & $92 \%$ & $20 / 20$ & $100 \%$ & $13 / 22$ & $59 \%$ \\
\hline Totais & $74 / 11$ & $64 \%$ & $60 / 9$ & $-62 \%$ & & \\
\hline
\end{tabular}

Tabela 3 - Índices referentes à ocorrência de $-\mathrm{R}$ retroflexo por contexto fônico na fala de 5 localidades de Campos-RJ, segundo

Brandão, 1988.

Duas observaçoes podem ser feitas sobre esses resultados. A realização retroflexa encontra-se presente na fala dos cinco informantes, em maior ou menor grau, o que demonstra que foi ou ainda é (quase 20 anos se passaram) uma característica presente no falar dessas comunidades, sobretudo nos contextos $\mathrm{V}-\mathrm{V}$ e $(\mathrm{C})(\mathrm{C})$ $\mathrm{V}$-no interior do vocábulo. No terceiro caso $(\mathrm{C}-\mathrm{V})$, torna-se menos produtivo, cedendo lugar, mesmo entre aqueles que o têm como pronúncia corrente, ao tepe alveolar ou ao apagamento.

Há, ainda, a mencionar o forte contraste entre as realizações dos informantes, que acabam por distribuir-se em dois grupos. Do primeiro, fazem parte os representativos de Mundéus, Furadinho e Farol de São Tomé, em cuja fala predominava a retroflexa. Do segundo, constam os de São Benedito e Ponta Grossa dos Fidalgos, que tinham no tepe e na fricativa velar/vibrante alveolar/tepe sua norma de pronúncia, respectivamente nos contextos $\mathrm{V}-\mathrm{V}, \mathrm{C}-\mathrm{V}$ e no contexto interno $(\mathrm{C})(\mathrm{C}) \mathrm{V}$ - .

Mais tarde, com nova amostra, em estudos de natureza sociolingüística sobre o $-\mathrm{R}$ em coda silábica, Brandão (1995, 1997), focalizando a fala de 13 comunidades do Norte e do Noroeste do 
Estado do Rio de Janeiro, verificou que, em contexto interno, num total de 1845 ocorrências, (5\%), correspondiam ao tepe, $21 \%$ à vibrante alveolar, $13 \%$ à aproximante retroflexa, 44\%, à fricativa velar, $8 \%$ à aspirada e $10 \%$ a cancelamento.

Eliminando-se as ocorrências de cancelamento em coda interna, as variantes [+ ant - entre elas computados o tepe, a vibrante e a aproximante retroflexa - correspondem a 43\% dos 1663 dados, enquanto as variantes [-ant] - as fricativas velar e aspirada - a 57\%, o que faz destas últimas a norma regional. Devido, no entanto, à significativa presença de variantes [+ ant], analisou-se sua aplicação, mostrando-se relevantes, em primeiro e segundo lugares, a faixa etária e a área geográfica e, em seguida as variáveis estruturais classe do vocábulo, contexto subseqüente e intensidade da sílaba. (p. 53).

$\mathrm{Na}$ faixa $\mathrm{C}(56$ anos em diante), concentram-se as variantes [+ant] (p. r. .79) e, na A, as [-ant] (p.r. .15), o que permite dizer que está em curso, na região, um processo de posteriorização de /R/, como mostra a Figura 1.

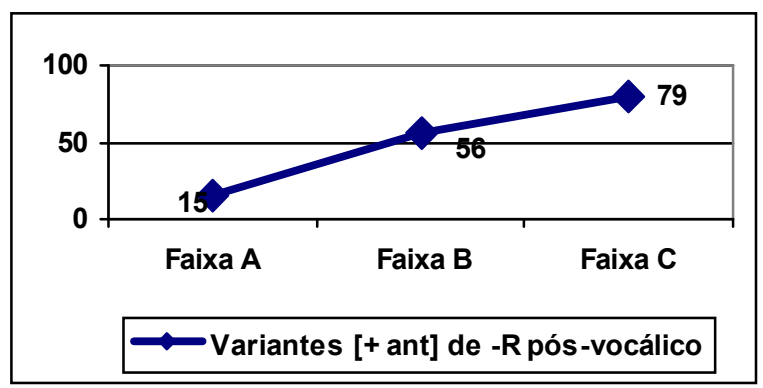

Figura 1 - Gráfico realizado com base em pesos relativos, segundo Brandão (1995, p. 53)

Quanto à área geográfica, ${ }^{7}$ as variantes [+ant], entre elas o tepe, predominam nas comunidades de perfil mais rural, quer litorâneas,

\footnotetext{
${ }^{7}$ Considerou-se área (a) litorânea mais rural: Barra do Itabapoana, Guaxindiba, Gargaú, Atafona, Farol de São Tomé; (b) litorânea menos rural: São João da Barra e Macaé; (c) interiorana mais rural: Cambuci, Ponta Grossa dos Fidalgos e São Benedito; (d) interiorana menos rural: São Fidélis, Itaocara e Itaperuna.
} 
quer interioranas, enquanto as [-ant] nas áreas menos rurais, isto é, mais urbanizadas.

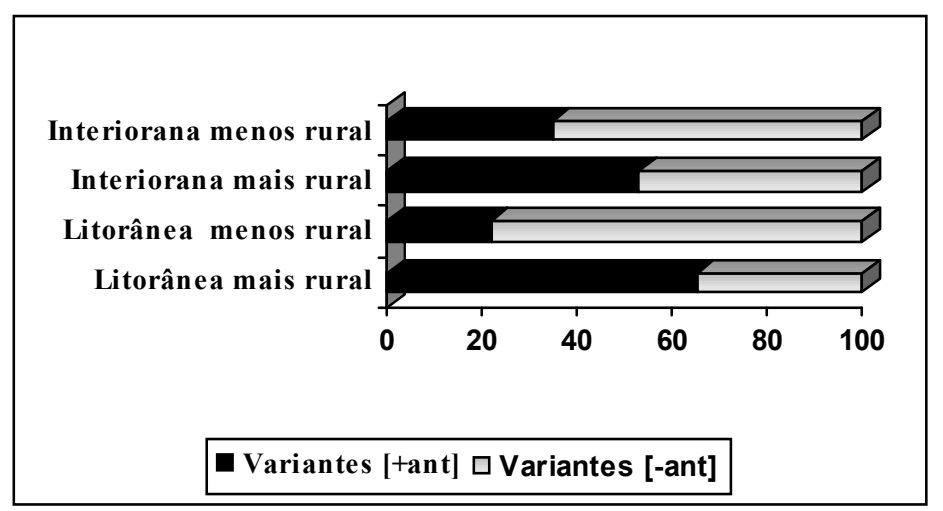

Figura 2 - Gráfico sobre a atuação da variável área geográfica na implementação das variantes de $-\mathrm{R}$ pós-vocálico (pesos relativos), com base em Brandão (1995).

Estudando o $-\mathrm{R}$ em coda silábica interna no falar de João Pessoa, com base em entrevistas do Projeto VALPB, Skeete (1997) mostra que, num universo de 9859 dados em que predominam as variantes fricativas (velar e glotal), 360 (4\%) correspondem à retroflexa. Devido à baixa produtividade desse fone, bem como do tepe e da vocalização (respectivamente 60 e 30 ocorrências), a autora analisou-as em conjunto, concluindo serem mais freqüentes entre indivíduos de mais de 50 anos (10\%), diminuindo o índice para 3\% entre os de meia idade até chegar a zero entre os mais jovens (p. 86). Uma gradação também se verifica em relação à variável escolaridade: os analfabetos $(20 \%)$ usam mais essas variantes do que os com um a oito (3\%) ou com nove ou mais anos (1\%) de instrução. Tal quadro é atribuído ao baixo prestígio social e ao caráter conservador dessas variantes (sobretudo da retroflexa), que são implementadas principalmente pelos homens.

Monaretto (1997) focaliza o $-\mathrm{R}$ na fala das três capitais do Sul, tanto na posição de coda quanto na de ataque silábico, com informantes do Corpus VARSUL distribuídos por grupo geográfico, gênero, faixa etária e níveis de escolaridade $\left(1^{\circ}\right.$ e $2^{\circ}$ segmentos do 
Ensino Fundamental e Ensino Médio). As variáveis mais relevantes para a implementação das variantes foram a posição na sílaba e a área geográfica, conforme se expõe na tabela a reproduzida a seguir (p. $31)$.

Tabela 2

Aplicação das variantes em cada grupo geográfico

\begin{tabular}{|c|c|c|c|c|c|}
\hline & Anterior & Posterior & Tepe & Retroflexa & $\begin{array}{l}\text { Total } \\
\text { na } \\
\text { Cidade }\end{array}$ \\
\hline Porto Alegre & $\begin{array}{l}199 \quad- \\
32 \% \\
.30\end{array}$ & $\begin{array}{l}432 \\
28 \% \\
.01\end{array}$ & $\begin{array}{l}821 \quad- \\
52 \% \\
.41\end{array}$ & $\begin{array}{l}46-21 \% \\
.20\end{array}$ & 1498 \\
\hline Florianópolis & $\begin{array}{l}4-1 \% \\
.04\end{array}$ & $\begin{array}{|ll|}959 & - \\
61 \% & \\
.99 & \\
\end{array}$ & $\begin{array}{l}268- \\
17 \% \\
.34 \\
\end{array}$ & $\begin{array}{l}1-0 \% \\
.01\end{array}$ & 1232 \\
\hline Porto Alegre & $\begin{array}{ll}424 & - \\
67 \% & \\
.66 & \\
\end{array}$ & $\begin{array}{|ll|}179 & - \\
11 \% & \\
.00 & \\
\end{array}$ & $\begin{array}{l}493- \\
31 \% \\
.25 \\
\end{array}$ & $\begin{array}{l}168 \\
78 \% \\
.78 \\
\end{array}$ & 1264 \\
\hline $\begin{array}{l}\text { Total de } \\
\text { aplic. } \\
\text { das variantes }\end{array}$ & \begin{tabular}{|l}
627 \\
803 \\
células \\
\end{tabular} & 1570 & 1582 & 215 & 3994 \\
\hline
\end{tabular}

Figura 3 - Tabela apresentada por Monaretto (1997, p. 31)

A retroflexa, que, no conjunto de dados das três cidades, apresentou 215 ocorrências, tem sua maior freqüência em Curitiba (78\%), seguida por Porto Alegre (21\%), em ambos os casos tanto em ataque quanto em coda silábica, conforme se depreende de outra tabela (p. 32). Em Florianópolis, dela só há um registro, em posição pósvocálica.

A variável faixa etária, apenas selecionada na análise da variante retroflexa, evidenciou que

individuos entre 25 e 50 anos são favorecedores (com peso relativo de .69) de tal forma, e as pessoas com mais de 50 anos desfavorecem-na 
(compeso de. 30). Isso revela que, ao contrário das estimativas de Amaral [...], esse som de $r$, apesar de estigmatizado, ainda existe.. (p. 34)

$\mathrm{Na}$ variedade culta, segundo trabalhos realizados no âmbito do Projeto NURC com dados de Recife, Salvador, Rio de Janeiro, São Paulo e Porto Alegre (Callou; Leite; Moraes, 1995, 1997), só se detectaram ocorrências da retroflexa nas duas últimas cidades, com índices, respectivamente, de $7 \%$ e 3\%.

Outros estudos, como os de Almeida (2004) sobre a fala do Vale do Cuiabá em Mato Grosso, Cohen (2006), sobre o sul de Minas e Taubaté-SP, corroboram a ampla distribuição da variante retroflexa, que foi analisada, do ponto de vista acústico, por Ferraz (2005), com apoio em dados de informantes de Pato Branco-PR.

\section{Considerações finais}

Não se pretendeu, aqui, realizar um levantamento exaustivo, nem ele o poderia ser, em vista do crescente número de pesquisas sobre variação lingüística já finalizadas ou em curso nas universidades brasileiras, sob a forma quer de dissertações e teses, quer de projetos de pesquisa, entre os quais o Atlas Lingüístico do Brasil (ALiB) que, ao revitalizar a geolingüística no país, acabou por incentivar o desenvolvimento de atlas de menor porte.

Essas pesquisas, aliadas a estudos norteados pelos princípios teórico-metodológicos da Sociolingüística Variacionista, que muito têm contribuído, desde a década de 1970, para o conhecimento do Português do Brasil, poderão, sem dúvida, lançar novas luzes sobre os condicionamentos estruturais e/ou sócio-históricos que originaram o $-\mathrm{R}$ retroflexo e alargar as trilhas esboçadas no mapa com que se encerra esta breve viagem por variedades rurais e urbanas dos falares do Norte e do Sul do Brasil. ${ }^{8}$

\footnotetext{
${ }^{8}$ No mapa, assinalam-se os Estados em que se conhecem registros de $-\mathrm{R}$ retroflexo, sem levar em consideração as suas áreas específicas de ocorrência ou seu maior ou menor índice de freqüência.
} 


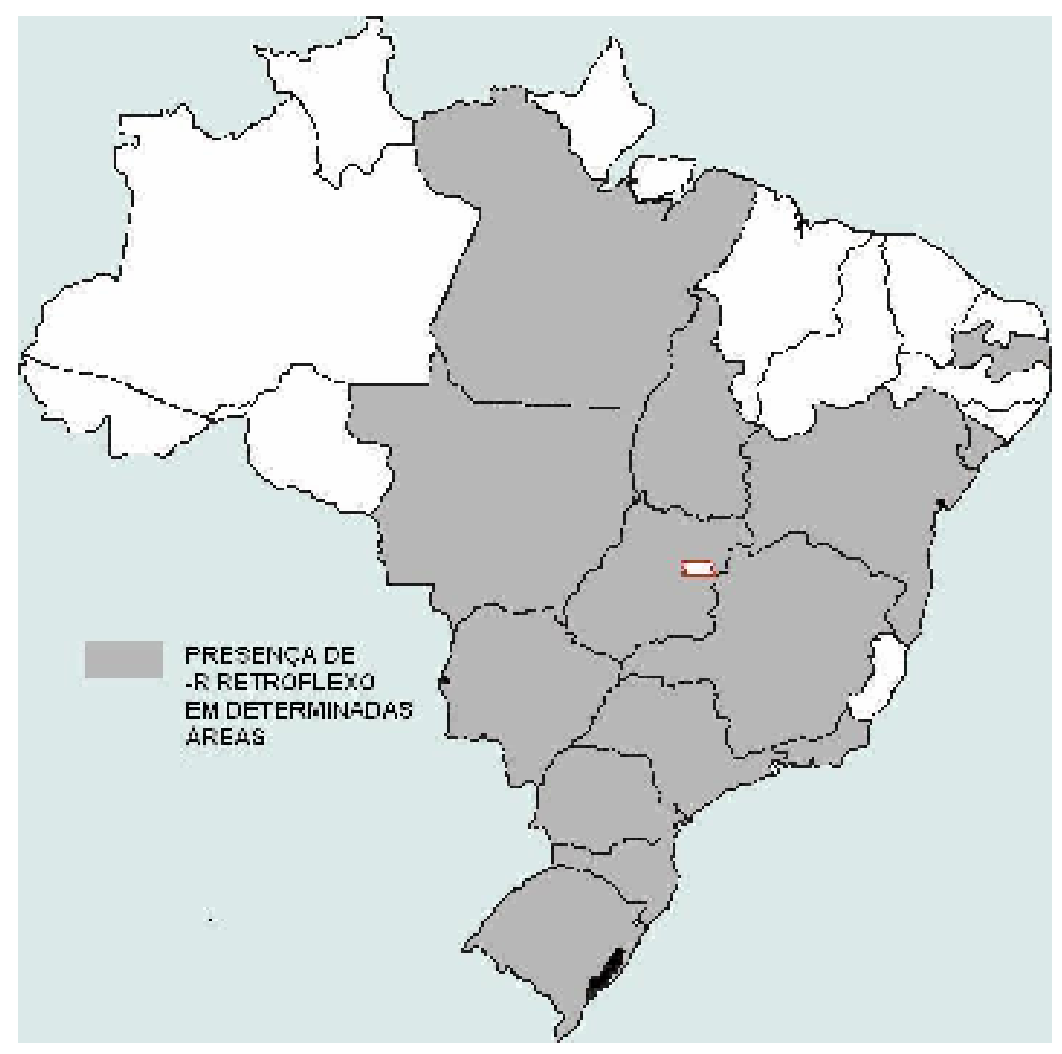

\section{Referências}

AGUiLERA, V. de A. Atlas Lingüistico do Paraná. Curitiba: Imprensa Oficial do Paraná, 1994.

Aspectos lingüisticos da fala londrinense. Esboço de um Atlas Lingüístico de Londrina. 1987.313f. Dissertação (Mestrado em Letras) - Universidade Estadual Paulista julio de Mesquita Filho, Assis. 2v.

ALMEIDA, Manoel M. S. As consoantes do português falado no Vale do Cuiabá. Signum - Estudos da Linguagem, Londrina, v. 7, n. 1, p. 149-163, 2004. 
AMARAL, Amadeu. O dialeto caipira. 3. ed. São Paulo: HUCITEC/ Secretaria da Cultura/Ciência e Tecnologia, 1976.

ARAgÃO, M. S.; MENEZES, C. Atlas Lingüistico da Paraíba. João Pessoa/Brasília: UFPB/CNPQ, 1984. 2v.

BRANDÃO, Silvia. Aspectos sociolingüísticos de um dialeto rural. In: HORA, Dermeval da (Org) Diversidade lingüistica no Brasil. João Pessoa: Idéia, 1997. p. 61-69.

O / R/ implosivo no Norte do Estado do Rio de Janeiro. In: PEREIRA, Cilene C.; PEREIRA, Paulo R. D. (org.) Miscelânea de estudos lingüísticos e literários in memorian Celso Cunba. Rio de Janeiro: Nova Fronteira, 1995. p. 49-58.

A geografia lingüistica no Brasil. São Paulo: Ática, 1991.

O pescador do Município de Campos: universo e linguagem. 1988. 490f. Tese (Doutorado em Letras Vernáculas) - Universidade Federal do Rio de Janeiro, Rio de Janeiro.

CALLOU, Dinah. Variação e diferenciação dialetal: a pronúncia do / r/ no português do Brasil. In: KOCH, I. V. (Org) Gramática do Português falado: desenvolvimentos. Campinas, UNICAMP, 1997. v. VI. p. 465493.

.; LEITE, Y; MORAES, J. Processo(s) de enfraquecimento consonantal no português do Brasil. In: ABAURRE, B.; RODRIGUES, A. (org) Gramática do Português falado: Novos estudos descritivos. v. VIII. Campinas, UNICAMP, 2002. p. 537-556.

CARDOSO, Suzana A. M. Atlas Lingüistico de Sergipe-II. Salvador: UDUFBA, 2005. $2 \mathrm{v}$.

COHEN, M. Antonieta. O "R" retroflexo no português brasileiro: descrição e percurso histórico. In: RAMOS, Jânia M. (Org) Estudos sociolingüísticos: os quatro vértices do GT da ANPOLL. Belo Horizonte: Faculdade de Letras da UFMG, 2006. 1 CD-ROM. 
CRUZ, M. L. C. Atlas lingüistico do Amazonas. 2004. 159f. Tese (Doutorado em Letras) - Universidade Federal do Rio de Janeiro, Rio de Janeiro. 2v.

FERRAZ, Irineu da Silva. Características fonético-acústicas do / $r /$ retroflexo do Português Brasileiro: dados de informantes de Pato Branco (PR). 2005. 123f. Dissertação (Mestrado em Letras) - Universidade Federal do Paraná, Curitiba.

FERREIRA, C. et al. Atlas Lingüistico de Sergipe. Salvador: UFBA/ FUNDESC, 1987.

FURLAN, O. A. Subsistência luso-açoriana na linguagem catarinense. 1982. Tese (Doutorado em Letras) - Universidade Federal do Rio de Janeiro, Rio de Janeiro.

HEAD, Brian. Propriedades fonéticas e generalidades de processos fonológicos: o caso do "R Caipira". Cadernos de Estudos Lingüísticos, Campinas, n. 13, p. 5-39, 1987.

Social factors in the perception of phonetic differences.

Cadernos de Estudos Lingüisticos, Campinas, n. 2, p. 158-166, 1981.

. Subsídios do Atlas Prévio dos Falares Baianos para o estudo de uma variante dialetal controvertida. Cadernos de Estudos Lingüisticos, Campinas, n. 1, p. 21-34, 1978.

.O estudo do r-caipira no contexto social. Revista de Cultura Vozes, v. 67, n. 8, p. 43-49, 1973.

KOCH, W.; KLASSMAN, M. S.; ALTEnHOFEN, C. V. Atlas Lingüístico-Etnogáfico da Região Sul do Brasil (ALERS). Vol. 1 Introducão; Vol. 2, Cartas Fonéticas e Morfossintáticas. Porto Alegre/ Florianópolis/ Curitiba: Ed. UFRGS/ Ed. UFSC/ Ed. UFPR, 2002.

LIMA, Alcides. A pronúncia do /r/ pós-vocálico na cidade de CametáPA. In: RAZKY, A. (Org.) Estudos Geo-Sociolingüisticos no Estado do Pará. Belém: UFPA, 2003. p. 54-78. 
LIMA, Luciana Gomes de. Atlas Fonético do entorno da Baía de Guanabara - AFeBG. 2006. 415f. Dissertação (Mestrado em Língua Portuguesa) Universidade Federal do Rio de Janeiro, Rio de Janeiro. 2 v.

MELO, Gladstone C. A língua do Brasil. 3. ed. Rio de Janeiro: Fundação Getúlio Vargas, 1975.

MONARETTO, Valéria N. O. Análise sociolingüística da vibrante no sul do Brasil. Graphos, João Pessoa, v. 2, n. 1, p. 25-34, 1995.

PEREIRA, Maria das Neves. Atlas Geolingüístico do Litoral PotiguarALiPTG. 2007. Tese (Doutorado em Letras) - Universidade Federal do Rio de Janeiro, Rio de Janeiro.

RAZKY, A. et al. Atlas Lingüistico Sonoro do Pará (ALISPA). Belém: CAPES/UFPA/UTM, 2004.

RIBEIRO, N. et al. Esboço de um Atlas Lingüístico de Minas Gerais. Rio de Janeiro: MEC/ Casa de Rui Barbosa/UFJF, 1977.

RODRIGUES, Ada N. O dialeto caipira na região de Piracicaba. São Paulo: Ática, 1974.

ROSSI, Nelson et al. Atlas Prévio dos Falares Baianos. Rio de Janeiro: MEC/INL, 1963

SILVA NETO, S. da. Introdução ao estudo da lingua portuguesa no Brasil. 2. ed. rev. e aum. pelo autor. Rio de Janeiro: Instituto Nacional do Livro; MEC, 1963.

Um traço de pronúncia caipira. In: Lingua, cultura e civilização; estudos de filologia portuguesa. Rio de Janeiro: Acadêmica, 1960.

SKEETE, Nadir A. O uso variável da vibrante na cidade de João Pessoa. Graphos, João Pessoa, v. 2, n. 1, p. 77-96, 1995. 